\title{
ANNOUNCEMENT
}

\section{Tropical Summer Clearance Sale}

Western Mesoamerica had a France-worth of tropical dry forest but today less than $2 \%$ remains. Only $0.09 \%$ has conservation status. The dry forest in Guanacaste National Park (GNP) in northwestern Costa Rica wants to buy itself, replant itself and regrow itself. This restoration of $700 \mathrm{~km}^{2}$ of dry forest and rain forest refugia will double the amount of Mesoamerican conserved dry forest.

How restore it? Give it back the land it once occupied, and protect it from ranching, fires, and hunting. The organisms come from the $302 \mathrm{~km}^{2}$ of National Park restoration already within GNP, and from population fragments in the damaged habitats. Invasion by native organisms will be natural or assisted, depending on the zone. But it is also cultural restoration. Its user-friendly performance as a living classroom and research laboratory will be conducted and attended largely by Costa Ricans, with an international audience as well. The Costa Rican government has agreed to match all donations $1: 1$ with endowment funds. GNP has raised $\$ 2.62$ million and needs at least $\$ 1$ million more for the small parts. She requires $\$ 4$ million more to purchase GNP's $160 \mathrm{~km}^{2}$ core. This purchase will secure the entire project.

Summer sale $-\$ 300$ buys you all of (forever):

1 hectare or 2.47 acres

0.001 jaguar

0.1 adult guanacaste tree

0.01 muscovy duck

0.0029 herp species

0.1 agouti

0.05 curassow

0.000016 of the join between $330 \mathrm{~km}^{2}$ dry

forest and $210 \mathrm{~km}^{2}$ rain forest

$1,000,000$ ants

10,000 mushrooms (early rainy season bargain)

0.25 tinamou

0.4 adult guapinol tree

0.5 parrot

5 metres of riverbank

0.005 tapir

1 rattlesnake

200 orchids

0.000029 volcano

0.0071 bird species
0.04 anteater

200 sphinx moth caterpillars (offer good in July only)

25 spiny pocket mice

0.429 insect species

0.01 white-lipped peccary

400 dung beetles

20 toads

125,000 acorns

0.023 mammal species

100 vines

$\mathbf{5 , 0 0 0}$ bruchid beetles (rainy season purchase not guaranteed)

100 scorpions

0.000028571 peripatus species

0.03 spider monkey

3 million unlisted organisms

20,000 cubic metres of sunshine, 4.7 billion raindrops, 1 ha of clouds and some dew.

Your tax-deductible Summer purchase order of any amount should be mailed to Nature Conservancy-Guanacaste Fund, 1785 Massachusetts Ave., NW, Washington, DC 20036. All purchases will be held for your on-site inspection by the Costa Rican National Park Service. Detailed information available from D. H. Janzen, Department of Biology, University of Pennsylvania, Philadelphia, PA 19104 (215-898-5636), or Santa Rosa National Park, Apdo. 169, Liberia, Guanacaste Province, Costa Rica (country code 506, tel. 69-55-98). 